looking at the phosphorylation of the MAP kinases p38, AKT and ERK after TNF $\alpha$ treatment and coincubation with YopM. Most interestingly, we found a strong reduction of osteoclast formation by YopM. Thus, incubation with YopM leads to a $90 \%$ reduction in osteoclasts precursors and osteoclasts in an osteoclast differentiation assay. YopM-Cy5 injected intra-articular into the knee joints of a mouse was detectable without a systemic distribution of YopM during a time period of $72 \mathrm{~h}$.

These results combined with the possibility for focused application in skeletal joints enhance the potential of YopM as a novel therapeutic agent for the treatment of inflammatory RA.

\title{
A118 THE BACTERIAL EFFECTOR PROTEIN YOPM IS A SELF- DELIVERING IMMUNE THERAPEUTIC AGENT THAT REDUCES INFLAMMATION IN RHEUMATOID ARTHRITIS
}

J Bertrand, C Rüther, J Scharnert, M Niedermeier, A Schmidt, T Pap

Institute of Experimental Musculoskeletal Medicine, University Hospital Muenster, Germany

\subsection{6/ard.2010.129635j}

Synovial fibroblasts (RASF) are active drivers of joint destruction in rheumatoid arthritis (RA) through the production of cytokines that maintain the inflammatory process. The Yersinia outer protein $\mathrm{M}$ (YopM) is an effector protein of pathogenic Yersinia and is able to enter host cells by membrane penetration and subsequent downregulation of inflammatory responses. Here, we investigated whether YopM has the potential to act as a 'self-delivering' immune therapeutic agent by exhibiting a beneficial effect on inflammation and joint destruction linked to RA.

We used human RASF as model cells to analyse the effects of YopM. First, we analysed the penetration of recombinant YopM into these cells by confocal laserscanning microscopy. Furthermore we investigated the effect of YopM on the production of interleukin 6 (IL- 6 ) and of the cartilage-degrading matrix-metalloproteinases MMP1 and MMP3 by ELISA. To unravel the potential mechanisms for these effects, we investigated the involvement of MAP-kinases and NF-KB signalling by Western Blot analysis. To investigate the effect of YopM on joint destruction we tested the effects of YopM on osteoclast differentiation. With respect to a potential in vivo application of YopM, we injected Cy5-conjugated YopM into mice and monitored the distribution within a timeframe of $72 \mathrm{~h}$ by fluorescence reflection imaging.

As seen in confocal scanning microscopy, YopM penetrates the cell membrane of human RASF and accumulates near the nucleus. In ELISA, we found a reduction of IL- 6 (83\%), MMP1 (75\%) and MMP3 (66\%) in supernatant of tumour necrosis factor $\alpha(\mathrm{TNF} \alpha)$ treated human RASF after incubation with YopM. We performed Western Blot analyses to study the underlying mechanisms and found a reduced activation of NF-KB after treatment with YopM and TNF $\alpha$. Interestingly, YopM reduces IKB $\alpha$ phosphorylation in TNF $\alpha$ stimulated RASFs significantly. We found no differences 